\title{
Fear of Online Consumer Identity Theft: Cross-country Application and
} Short Scale Development

Walsh, Gianfranco; Shiu, Edward; Hassan, Louise; Hille, Patrick; Takahashi, Ikuo

\section{Information Systems Frontiers}

DOI:

10.1007/s10796-019-09958-2

Published: 01/12/2019

Peer reviewed version

Cyswllt i'r cyhoeddiad / Link to publication

Dyfyniad o'r fersiwn a gyhoeddwyd / Citation for published version (APA):

Walsh, G., Shiu, E., Hassan, L., Hille, P., \& Takahashi, I. (2019). Fear of Online Consumer Identity Theft: Cross-country Application and Short Scale Development. Information Systems Frontiers, 21(6), 1251-1264. https://doi.org/10.1007/s10796-019-09958-2

\footnotetext{
Hawliau Cyffredinol / General rights

Copyright and moral rights for the publications made accessible in the public portal are retained by the authors and/or other copyright owners and it is a condition of accessing publications that users recognise and abide by the legal requirements associated with these rights.

- Users may download and print one copy of any publication from the public portal for the purpose of private study or research.

- You may not further distribute the material or use it for any profit-making activity or commercial gain

- You may freely distribute the URL identifying the publication in the public portal?
}

Take down policy

If you believe that this document breaches copyright please contact us providing details, and we will remove access to the work immediately and investigate your claim. 


\title{
Fear of Online Consumer Identity Theft: Cross-country Application and Short Scale Development
}

\author{
Gianfranco Walsh $^{\mathrm{a} *}$, Edward Shiu $^{\mathrm{b}}$, Louise Hassan ${ }^{\mathrm{b}}$, Patrick Hille ${ }^{\mathrm{a}}$, Ikuo Takahashi ${ }^{\mathrm{c}}$
}

${ }^{a}$ Friedrich-Schiller University of Jena, Department of General Management \& Marketing, Carl-ZeissStrasse 3, 07743 Jena, Germany, Phone 00493641 943110, Fax 00493641 943112, walsh@unijena.de, patrick.hille@uni-jena.de

${ }^{b}$ Bangor University, Bangor Business School, College Road, Bangor, LL57 2DG, Wales, Phone 0044 1248382161 (Shiu), 00441248383280 (Hassan), e.shiu@bangor.ac.uk, 1.hassan@ bangor.ac.uk

${ }^{\mathrm{c}}$ Keio University, Faculty of Business and Commerce, 2-15-45 Mita, Minat-ku, Tokyo 108-8345, Japan, Phone 008135427 1280, itaka1104@gmail.com

Corresponding Author: Gianfranco Walsh, Phone 00493641 943110,walsh@uni-jena.de

Revised manuscript submitted to special issue of Information Systems Frontiers, "Cyber Security, Privacy and Ethics of IS" (in honor of Professor H. Jeff Smith), September 2019

\section{Acknowledgement}

This research was partly funded by the German Research Foundation (Deutsche Forschungsgemeinschaft); WA 1568/9-1 - AOBJ: 568047. 


\title{
Fear of Online Consumer Identity Theft: Cross-country Application and Short Scale Development
}

\begin{abstract}
The growing internationalization of electronic commerce demands the establishment of the crossnational validity of theoretical concepts. An important concept in e-commerce is consumers' fear of online identity theft (FOIT), which impedes consumers' willingness to engage in online transactions and can negatively affect e-commerce revenues. The present study validates the consumer FOIT scale developed in Germany by Hille, Walsh, and Cleveland (2015) in a cross-cultural setting and proposes an abbreviated version of the scale, which is approximately $35 \%$ shorter than the original. Established validation procedures with samples of online consumers from Germany, the United States, and Japan demonstrate the reliability, validity, and cross-national applicability of the short FOIT scale. In particular, this study extends Hille et al.'s (2015) research by examining and revealing the impact of FOIT on consumers' prevention-focused responses. This research offers implications for both research and e-commerce managers.
\end{abstract}

Keywords: Cross-cultural scale validation, Fear of online identity theft, Prevention-focused responses, E-commerce 


\section{Introduction}

E-businesses such as Rakuten (Japan), Alibaba (China), Zalando (Germany), and Amazon (U.S.) are widening their international reach. E-commerce firms increasingly market their offerings internationally, such that HBO expanding its Web-only service to South American countries, with a strong presence in more than 30 territories across Central and South America and the Caribbean (Littleton 2017), and Gear4Music, a UK online retailer, aims to become the world's leading internet vendor of music instruments and equipment by growing in Europe and beyond (Rigby 2019). Similarly, ASOS, a UK online retailer, developed into a global internet fashion vendor in the last decade offering products in more than 230 countries worldwide (Kulach 2019). The global reach of such companies suggests the need for e-commerce managers to be increasingly sensitive to cultural differences and their effects on consumers' online shopping behaviors, their expectations of online shopping environments (Davis et al. 2008; Mazaheri et al. 2014). E-commerce managers need also take note of consumers' perceptions of psychological barriers, which may prevent consumers who share personal information online from providing the necessary personal and financial information to complete online transactions (Bellman et al. 2004; Gupta et al. 2010).

A key psychological barrier is consumers' fear of online identity theft (Martin et al. 2017; Xu and Gupta 2009). Such fears can affect consumers' decisions to buy online and thus e-businesses' bottom-line performance (Hinz et al. 2015; Lee and Lee 2012; Martin and Murphy 2017; Zafar et al. 2012). Thus e-businesses seek to develop consumer-friendly online shopping environments and builtin transaction processes that make online transactions as effortless and secure as possible (e.g., Lee and Lin 2005). For example, the U.S.-based department store chain Macy's sells and ships goods to consumers in more than 100 countries, in partnership with Borderfree Ecommerce, a third-party service that helps the retailer send online purchases around the globe easily and securely (Macy's 2019). As more people shop online, many consumers understandably fear being defrauded or 
victimized as a result of stolen identity credentials (e.g., Albashrawi and Motiwalla 2019; Fico 2017; Roberts et al. 2013): Identity theft has been one of the primary reasons for U.S. consumers to file complaints with the Federal Trade Commission in the past decade (FTC 2018), with data breaches continuing on the increase (Green and Hanbury 2018). The prevalence of these incidents creates an environment of fear and reluctance to divulge personal details to e-commerce providers (Zafar et al. 2016). Accordingly, Lin, Wang, and Tsai (2016, p. 71) call identity theft "one of the most severe threats to the security of online transactions associated with e-commerce services."

To investigate this consumer phenomenon, Hille, Walsh, and Cleveland (2015) introduced a measurement scale for consumers' fear of online identity theft (FOIT), defined as a negative consumer emotion activated by consumers' cognitive appraisal of the possibility of the theft of personal and financial data when conducting transactions online. However, the uptake of the scale has been slow and relatively limited. Compared to other psychometric scales published in the same year (e.g., Vernuccio et al.'s (2015) eight-item 'social-interactive engagement scale') the FOIT scale is not cited many times and there is little reported data for different populations. One reason for this may be the length of the original FOIT scale, being 11 items long. Even though it is widely accepted that long scales are superior to short ones (because long scales are better able to assess broad and heterogeneous constructs, tend to achieve acceptable reliability, etc.), short scales are often preferred for pragmatic reasons (Postmes et al. 2013). Shorter scales, defined as scales "measuring a specific psychological construct with fewer than, say, 10 items" (Ziegler et al. 2014, p. 185), are practically useful, especially in situations "where many variables are under examination" (Henningham 1996, p. 517) and where longer scales may lead to acquiescent responding and sub-optimal response rates (Breaugh and Colihan 1994; Edwards et al. 2004). In addition, in research efforts for which FOIT is not the main construct of interest, researchers might exclude this measure to keep the survey short, or could use different subsets of items based on some heuristic decision. By validating the short FOIT 
scale, the present study provides a scale that is both parsimonious and resonant with the original conceptualization of the FOIT construct (cf. Ruvio et al. 2008). As the original long scale, the short scale can be used by researchers and e-business (e.g., as a quality measurement tool).

The rationale of the present study is therefore to propose and validate a shorter version of the FOIT scale. Replication studies that hold constant certain parameters (e.g., the focal measure) while changing others are advocated in information system research (Berthon et al. 2002). The challenge in this effort is that competing goals exist in terms of scale length, namely, high content validity vs. short survey-completion time (Hinkin 1995). The present study is premised on the assumption that there is merit in shortening scales because short scales can combine measurement efficiency with validity (cf, Walsh et al. 2009). As part of the validation effort, this research extends the work by Hille et al. (2015) by examining prevention-focused behaviors (Wirtz and Lwin 2009) as FOIT outcomes. Our study therefore can be considered a replication and extension study (Berthon et al. 2002). Studying these behaviors is important for e-businesses who aim to gain a better understanding of consumer reactions to their fears of identity theft. As a corollary, this research considers that measurement instruments developed in one country may not be readily used in others.

The development of the FOIT scale took place in a German e-commerce context, which might differ from other cultural contexts with regard to the design of online shopping environments and consumers' general expectations (Cyr et al. 2010). For example, protecting privacy and refraining from disclosing personal information are particular characteristics of German behavior (e.g., Berendt et al. 2005). An expanding body of research investigates cultural differences in consumer online shopping behaviors (e.g., Smith et al. 2013; Sun 2011). Mazaheri et al. (2014, p. 255) suggest that consumers' online shopping behaviors differ across cultures because consumers from different cultures "display significant differences in how they perceive website atmospherics, as well as how these influence their perceptions of service tangibility and their attitudes." In their cross-cultural U.S. 
and Chinese study, Davis et al. (2008) provide empirical evidence that culture-based perceptions affect online customers' responses to atmospheric cues. Taken together, past research suggests crosscultural differences in online shopping and information disclosure and may raise the question of whether the FOIT scale possesses cross-cultural validity. Therefore, scholars might be reluctant to adopt the scale to measure FOIT in other countries.

Because e-commerce managers might be more receptive to a shorter FOIT scale that has undergone a thorough reexamination in other cultural contexts, the present study seeks to achieve both these benefits. Walsh et al. (2015) argue that, for measurement scales in particular, assessing the psychometric properties and validity across countries is indispensable before a scale can be considered generalizable. Moreover, consumers' fear of online identity theft is of great interest to ecommerce scholars and practitioners around the world, assessing the generalizability of the FOIT scale and developing a short form is appropriate. Therefore, this study develops and assesses an abbreviated version of the FOIT scale (35\% shorter than the original scale), in terms of cross-country validity and applicability, using data from Germany, the United States, and Japan. The three countries investigated in the current research are among the five largest e-commerce markets in the world (Herpin 2018), and online identity theft is prevalent in them. Furthermore, the three countries have different privacy rules, with the United States operating a somewhat laxer regime than Germany and Japan (European Commission 2018). The United States and Japan also represent highly distinct cultures from the original location for the scale development: Japan is more culturally distant, whereas the United States is less culturally distant, relative to Germany (Stahl and Caligiuri 2005). The three countries vary in their levels of uncertainty avoidance, such that Japan tends to score higher on this measure of how uncomfortable people feel in novel or ambiguous situations, the United States scores low, and Germany falls roughly in the middle (Hofstede 2019). 
E-commerce managers would also benefit from an understanding of possible consumers reactions to their fears of identity theft. Toward this aim, the current research theorizes and assesses three likely FOIT-related consumer prevention-focused behaviors that would negatively affect firm's ability to communicate and/or obtain valid information from their customer base (Wirtz and Lwin 2009).

\section{Background}

\subsection{Online Identity Theft}

Consumer-friendly online shopping environments and processes need to address privacy considerations, and research needs to determine how consumers incorporate privacy considerations into their online purchasing decisions (Martin et al. 2017; Tsai et al. 2011). Identity theft and data breaches are global phenomena (Targett 2018) that spark widespread reluctance to divulge personal details to e-commerce providers, and the problem is a global one (e.g., Crossler et al. 2019). In the United States, the personal and bank account information of almost one in every five Internet users has been stolen (Madden 2014). The number of identity theft victims increase year on year, affecting 16.7 million consumers with fraudsters stealing \$16.8 billion from U.S. consumers in 2017 (Pascual, Marchini, and Miller 2018). In Germany, the Federal Office for Information Security reported the theft of 16 million e-identities and passwords in 2014 (ENISA 2014), and then later the same year, another 18 million e-mail addresses and passwords were hacked by cyber criminals and used for illicit online purchases (Avasthy 2014). A more recent 2018 report reveals that identity thefts are ever increasing in Germany, with a 2017 report from the Federal Criminal Police Office (BKA) detailing the discovery of 500 million stolen data records containing e-mail addresses with corresponding passwords (Federal Office for Information Security 2018). Japanese consumers also have suffered widespread online identity theft, including 22 million stolen user identities from Yahoo Japan 
Corporation in 2013 (The Japan Times 2013), 2 million stolen personal data sets from 140 companies in 2015 (The Japan Times 2016) and 320,000 customer records, including credit card details, from just 400 lodging providers in 2018 (The Japan Times 2018). Thus, all three countries are appropriate sites for assessments of the FOIT scale.

\subsection{The FOIT Scale and Validation Procedures}

Hille et al. (2015) conducted one qualitative and three quantitative studies in Germany to examine the nature of FOIT and identify behavioral correlates. They confirmed two FOIT dimensions derived from prior literature (i.e., fear of financial loss, fear of reputational damage). Using individual, indepth, phenomenological interviews, these authors asked informants about online identity theft and the feelings that a potential loss of identity would evoke. The interviews revealed that when consumers navigate online environments, negative feelings accumulate and then evolve into fear if not alleviated. Building on the results of the qualitative study, Hille et al. (2015) developed an 11item, two-dimensional FOIT scale, established content validity, and examined the quantitative relationships of their scale with online trust, online privacy concerns, and online purchase intentions. According to their results, consumers' online trust and privacy concerns relate to FOIT, and differences in FOIT in turn relate to consumers' online purchase intentions. Both FOIT dimensions achieved reliabilities (alpha) of .95, demonstrating good internal consistency. In a confirmatory factor analysis with the 11 FOIT items, the factor loadings for the FOIT items ranged from .79 to .95 , suggesting an internally consistent, two-dimensional construct.

The present study investigates the feasibility of the full and an abbreviated FOIT scale across three distinct cultural contexts: Germany, the United States, and Japan. To develop the short FOIT scale and validate it cross-culturally, this study adopts the procedure and criteria (judgmental, internal, and external) suggested by Nenkov, Morrin, Ward, Schwartz, and Hulland (2008). 
Judgmental validity relates to readability; internal criteria refer to the internal consistency and dimensionality; and external criteria pertain to construct validity measures, such as predictive and nomological validity. Applying these criteria rigorously is important to achieve an acceptable tradeoff between the reduction in item numbers and reduction in validity (Smith, McCarthy and Anderson 2000). An additional assessment of measurement invariance was also undertaken for both the 11-item and the short FOIT scales.

\subsection{FOIT and Prevention Behaviors}

Extending Hille et al.'s (2015) validation approach, the current research theorizes that FOIT likely predicts prevention-focused behaviors (Wirtz and Lwin 2009). Prevention-motivated consumers want to feel secure and stay safe and are concerned with achieving progress that restores the status quo. In this case, the status quo is a situation in which the consumer no longer perceives the negative emotions engendered by FOIT. These behaviors relate to safety and the prevention of negative outcomes. In a FOIT context, prevention-focused behaviors imply strategies adopted by consumers to protect their privacy and avoid the potential of identity theft. One can thus reason that FOIT may activate prevention-focused behaviors, which is why they are considered as outcomes in this study. Wirtz and Lwin (2009) identify three prevention-focused behaviors: deflective behaviors, or shielding actions (e.g., disguising identities) to avoid communications and data collection efforts from marketers; defensive behaviors, which are proactive (e.g., requests to remove names from mailing lists) to force companies to stop collecting information about them; and disruptive behaviors, which are retaliatory (e.g., negative word of mouth) and undertaken by consumers who are dissatisfied with the company's privacy practices.

Building on Wirtz and Lwin (2009), who demonstrate a causal link between privacy concerns and prevention-focused behaviors, the current research examines the extent to which FOIT might lead to consumer engagement with such prevention-focused behaviors. To assess the predictive 
validity of the FOIT scale, this study uses a structural model with the 11-item and a short version of the FOIT scale as independent variables, together with the three prevention-focused behaviors as dependent variables.

\section{Method}

The online questionnaire for all three countries included the 11 FOIT items; the U.S. and Japan questionnaire versions also contained items to measure the three presumed correlates of deflective, defensive, and disruptive behaviors (Wirtz and Lwin 2009). Hille et al. (2015) employed five-point Likert scales for their German sample; items were also anchored on five-point scales for the U.S. and Japanese samples in the present study ( $1=$ "strongly disagree" and $5=$ "strongly agree"). To ensure the equivalence of the FOIT scale, bilingual native English and Japanese speakers applied a backtranslation approach to all the scales (Van Auken et al. 2006).

The German data $(n=1,150)$ came from Hille et al. (2015), who used it in their study 3 . The U.S. participants came from Amazon Mechanical Turk (MTurk). Only participants with high approval rates on MTurk (> 95\% approval on at least 1,000 tasks) could join the study. Given that past evaluations of data quality show that data collected from MTurk compares favorably to data collected in person or via social networking websites (e.g., Casler et al. 2013), our data collection approach can be deemed appropriate. Data from 496 qualifying U.S. online shoppers were collected. In Japan, a survey link sent to students attending a market research class asked them to disseminate the link among their (student and non-student) peers, via e-mail and social media. The participants received information that the survey was about “online shopping.” Following Hille et al.'s (2015) procedure, participants first specified online retailers from a list of possible e-retailer choices, such as Amazon and Rakuten, then were advised that all subsequent questions would be asked relative to 
their experiences with one of these online retailers. The data collection yielded a sample of 334

respondents. Table 1 provides the descriptions of the survey designs and samples.

Table 1 Data collection method and sample descriptions

\begin{tabular}{|c|c|c|c|}
\hline & $\begin{array}{c}\text { Study 1: Germany } \\
\text { Reexamining Hille et al. (2015)* }\end{array}$ & Study 2: United States & Study 3: Japan \\
\hline Purpose & $\begin{array}{l}\text { Assessment of measurement } \\
\text { invariance of FOIT scale. } \\
\text { - Development of shortened } \\
\text { scale. }\end{array}$ & $\begin{array}{l}\text { - Development of shortened } \\
\text { scale. } \\
\text { - Validation of FOIT scale. } \\
\text { - Assessment of measurement } \\
\text { invariance of FOIT scale. } \\
\text { - Assessing predictive validity } \\
\text { of FOIT. }\end{array}$ & $\begin{array}{l}\text { - Development of shortened } \\
\text { scale. } \\
\text { - Validation of FOIT scale. } \\
\text { - Assessment of measurement } \\
\text { invariance of FOIT scale. } \\
\text { - Assessing predictive validity } \\
\text { of FOIT. }\end{array}$ \\
\hline $\begin{array}{l}\text { Survey } \\
\text { Design }\end{array}$ & $\begin{array}{l}\text { Data collected by online } \\
\text { questionnaire, with a link to the } \\
\text { questionnaire sent by email to a } \\
\text { random sample of } 3,000 \text { panel } \\
\text { members. Online music context. } \\
\text { Participants were randomly } \\
\text { assigned to music provider with } \\
\text { which they had prior experience. }\end{array}$ & $\begin{array}{l}\text { Data collected by online } \\
\text { questionnaire through Amazon's } \\
\text { MTurk. Respondents filled in } \\
\text { questionnaire about either an e- } \\
\text { retailer they had prior experience } \\
\text { with or looked at the website of } \\
\text { an e-retailer and then filled out } \\
\text { the questionnaire with it in mind. }\end{array}$ & $\begin{array}{l}\text { Data collected by online } \\
\text { questionnaire, with links to the } \\
\text { questionnaire disseminated by } \\
\text { students by email and social } \\
\text { media to a convenience sample of } \\
\text { consumers who shop online. } \\
\text { Participants randomly assigned to } \\
\text { online retailer with which they } \\
\text { had prior experience. }\end{array}$ \\
\hline Sample & $\begin{array}{l}\mathrm{n}=1,150(\text { aged } 18 \text { to } 73 \text { years }) \\
45 \% \text { female } \\
\text { Mean age }=38.3(\mathrm{SD}=12)\end{array}$ & $\begin{array}{l}\mathrm{n}=496(\text { aged } 19 \text { to } 83 \text { years }) \\
56 \% \text { female } \\
\text { Mean age }=39.6(\mathrm{SD}=13)\end{array}$ & $\begin{array}{l}\mathrm{n}=334(\text { aged } 18 \text { to } 85 \text { years }) \\
46 \% \text { female } \\
\text { Mean age }=23.9(\mathrm{SD}=7)\end{array}$ \\
\hline
\end{tabular}

*The original data set was obtained from Hille et al. (2015).

\section{Results}

\subsection{Identifying Items for the Short FOIT Scale}

The process for developing the short FOIT scale relied on conceptual considerations and empirical criteria. Conceptually, the original 11-item FOIT scale consists of two dimensions: fear of financial losses (FFL, eight items) and fear of reputational damage (FRD, three items). Therefore, a more balanced FOIT scale, representative of both construct dimensions, might result if the scale-shortening process focuses on the FFL dimension. The central empirical criteria, that were relevant to the selection of items for the short scale, were judgmental and internal validity. For judgmental validity, a key measure of item quality is readability (Nenkov et al. 2008). Samples of 32 German, 40 U.S., and 43 Japanese consumers indicated the ease of understanding of each item from the FOIT scale (seven-point scale, anchored by "not very easy to understand" [1] and "very easy to understand" [7]). 
Appendix 1 summarizes the readability ratings, on which three items (FFL1, FFL6, and FFL8) achieved means lower than 6 , indicating only moderate readability relative to the other items. For internal validity, the criteria assessed across all three country samples were the item-to-subscale correlation, item-to-total correlation, and factor loadings. Items FFL6, FFL7, and FFL8 performed worse than the other FFL items (see Appendix 1). Together with FFL1, these three items also exhibit slightly lower loadings than the other FFL items (see Table 2). Therefore, the judgmental and internal criteria together suggest excluding items FFL1, FFL6, FFL7, and FFL8 from the FOIT scale to arrive at the 7-item short FOIT scale.

\subsection{Psychometric Properties of the FOIT and FOIT-Short Scales}

Table 2 details the analyses undertaken (using AMOS version 23) for the present research, starting with the results of the 11-item, two-factor structure used to test the psychometric properties of the collected data, according to a comparison of the confirmatory factor analysis (CFA) results with Hille et al.'s (2015) results, to establish if the psychometric properties of the data are similar. Table 2 contains the Cronbach's alpha values and average variance extracted (AVE) for each subscale, the factor loadings, and the model fit measures. The reliability of each subscale is very good, with alpha values greater than .9 with the exception of fear of reputational damage in the U.S. (.84). The AVE values for both subscales exceed the recommended level of .5; the lowest AVE value is .66, again for fear of reputational damage in the U.S. (Fornell and Larcker 1981). The standardized loadings are acceptable (lowest $=.67$ ) and statistically significant within each country. The fit of the CFA models is good for the German and U.S. samples but poor for the Japanese sample. Across studies, correlations between the subscales are equal to .70 for Germany, .63 for the U.S., and .76 for Japan. The assessment of discriminant validity between the two subscales still met the criteria set out by 
Fornell and Larcker (1981), such that for each country sample, the square of the correlation between the two subscales is smaller than both AVE values.

To assess discriminant validity of the two construct dimensions (FFL and FRD) for the FOIT long and short scale, the authors applied an additional criterion-the heterotrait-monotrait ratio of correlations (HTMT; Henseler et al. 2015). An HTMT value below .90 indicates discriminant validity between two reflective constructs. The results of the HTMT analyses show that all HTMT ratios are below the .90 threshold (see Appendix 2); for the German FOIT full scale the HTMT ratio is close to .9 (HTMT ratio=.89), however, the German short scale yields a much better ratio of .53 , indicating the appropriateness of the short scale.

Regarding the psychometric properties of the short FOIT scale across the three country samples, the Cronbach's alpha values for the FFL subscale are very similar to those of the full scale and are greater than .9. The AVE values remain at or above the recommended threshold of .5. The fit of the CFA model for the short FOIT scale show improvements in the fit statistics for Germany and Japan, with a slight decrease in fit due to a higher root mean square error of approximation (RMSEA) value for the United States. Overall the fit of the model is acceptable for Germany and the U.S. but poor for Japan. The standardized loadings are .77 or greater, very similar to the values obtained for the full scale. Finally, the correlations between the two FOIT dimensions are slightly reduced for the short scale, with correlation values of .68 for Germany, .62 for the U.S., and .71 for Japan. 
Table 2 Standardized CFA factor loadings and summary psychometric data for full and short scales

\begin{tabular}{|c|c|c|c|c|c|c|}
\hline \multirow[t]{2}{*}{ Construct and items/Fit statistics } & \multicolumn{2}{|c|}{ Hille et al.’s (2015) study 3} & \multicolumn{2}{|c|}{ Study 2: United States } & \multicolumn{2}{|c|}{ Study 3: Japan } \\
\hline & Full scale & Short scale & Full scale & Short scale & Full scale & Short scale \\
\hline Fear of financial losses (FFL) & $\begin{array}{c}\alpha=.95 \\
\mathrm{AVE}=.71\end{array}$ & $\begin{array}{c}\alpha=.92 \\
\mathrm{AVE}=.75\end{array}$ & $\begin{array}{c}\alpha=.96 \\
\mathrm{AVE}=.77\end{array}$ & $\begin{array}{c}\alpha=.95 \\
\mathrm{AVE}=.83\end{array}$ & $\begin{array}{c}\alpha=.95 \\
\mathrm{AVE}=.71\end{array}$ & $\begin{array}{c}\alpha=.95 \\
\mathrm{AVE}=.82\end{array}$ \\
\hline $\begin{array}{l}\text { (1) I am afraid that somebody could steal my money while I am transferring } \\
\text { my personal data online. }\end{array}$ & .86 & & .87 & \multicolumn{3}{|c|}{.75} \\
\hline $\begin{array}{l}\text { (2) I am scared that a criminal could use my bank account number to do online } \\
\text { shopping in my name. }{ }^{\text {a }}\end{array}$ & .88 & .90 & .91 & .90 & .87 & .87 \\
\hline $\begin{array}{l}\text { (3) I am scared that a criminal could use my credit card account number to do } \\
\text { online shopping in my name. }{ }^{\text {a }}\end{array}$ & .78 & .77 & .92 & .92 & .90 & .92 \\
\hline (4) I am frightened that somebody could do online shopping at my expense. ${ }^{a}$ & .89 & .89 & .91 & .90 & .90 & .93 \\
\hline $\begin{array}{l}\text { (5) I am worried about an unauthorized person making online purchases using } \\
\text { my personal data. }{ }^{\text {a }}\end{array}$ & .88 & \multirow[t]{4}{*}{.91} & .90 & .90 & .90 & \multirow[t]{4}{*}{.90} \\
\hline $\begin{array}{l}\text { (6) I am scared that when I have to give my credit card number to shop online } \\
\text { that it could be misused. }\end{array}$ & .79 & & .90 & & .81 & \\
\hline $\begin{array}{l}\text { (7) I am scared that when I have to give my bank account number to shop } \\
\text { online that it could be misused. }\end{array}$ & .81 & & .82 & & .82 & \\
\hline $\begin{array}{l}\text { (8) The thought that a stranger could gain access to my customer account at an } \\
\text { online store by using my personal data frightens me. }\end{array}$ & .82 & & .79 & & .78 & \\
\hline Fear of reputational damage (FRD) & \multicolumn{2}{|c|}{$\begin{array}{c}\alpha=.95 \\
\mathrm{AVE}=.86\end{array}$} & \multicolumn{2}{|c|}{$\begin{array}{c}\alpha=.84 \\
\mathrm{AVE}=.66\end{array}$} & \multicolumn{2}{|c|}{$\begin{aligned} \alpha & =.93 \\
\mathrm{AVE} & =.83\end{aligned}$} \\
\hline $\begin{array}{l}\text { (9) I am frightened of somebody using my personal data on the Internet in } \\
\text { order to run me down. }{ }^{\text {a }}\end{array}$ & .89 & .89 & .67 & .67 & .80 & .80 \\
\hline $\begin{array}{l}\text { (10) I am very worried that the unauthorized use of my personal data online } \\
\text { could damage my reputation. }{ }^{\text {a }}\end{array}$ & .95 & .95 & .87 & .87 & .97 & .97 \\
\hline $\begin{array}{l}\text { (11) I am worried about my reputation being damaged due to the illegal use of } \\
\text { my personal data online. }{ }^{\text {a }}\end{array}$ & .94 & .94 & .88 & .88 & .95 & .95 \\
\hline \multicolumn{7}{|l|}{ CFA fit statistics } \\
\hline$\chi^{2} /$ Degree of freedom & 3.81 & 2.62 & 3.87 & 4.74 & 10.35 & 8.17 \\
\hline Confirmatory fit index & .99 & 1.00 & .98 & .98 & .90 & .96 \\
\hline Tucker-Lewis index & - & 1.00 & .97 & .97 & .87 & .94 \\
\hline Root mean square error of approximation (RMSEA) & .049 & .038 & .076 & .087 & .168 & .147 \\
\hline RMSEA 90\% CI Lower bound & - & .022 & .064 & .066 & .154 & .122 \\
\hline RMSEA 90\% CI Upper bound & - & .053 & .089 & .109 & .182 & .173 \\
\hline
\end{tabular}

Notes: $\alpha=$ Cronbach's alpha; AVE = average variance extracted; CI = confidence interval. Items 3, 6 , and 9 were freed to achieve partial metric invariance for the full scale and items 3 and 9 were freed for the short scale.

${ }^{a}$ Items chosen for the seven-item short FOIT scale. 
Next, the performance of items and the overall scale was assessed by computing average factor loadings (Weijters et al. 2009). Appendix 3 contains the average factor loadings for the 11item long and 7-item short scale across the three countries. Results show that the short scale performs as well, if not better than the longer 11-item version.

\subsection{Measurement Invariance of the Full and Short FOIT Scale}

To test the measurement equivalence of the short FOIT scale across the three countries, the analysis of the two-factor correlated model followed the procedures outlined by Steenkamp and Baumgartner (1998). The minimal requirement is evidence of configural invariance; however, for scales that aim to explore relationships between constructs, evidence of metric invariance is also important. Metric invariance ensures the equality of the scale intervals across samples. Table 3 provides the results of the assessments of configural and metric invariance. Configural invariance exists for the two-factor short FOIT scale; partial metric invariance $\left(\Delta \chi^{2}=.849, \Delta_{\mathrm{df}}=6, p>.9\right)$ also receives support across the three country samples after freeing two items (items 3 and 9 in Table 2). An examination of the full 11-item FOIT scale yields partial metric invariance $\left(\Delta \chi^{2}=\right.$ $13.425, \Delta \mathrm{df}=12, p=.339$ ) across the three country samples after freeing items 3,6 , and 9 (see

Table 2).

Table 3 Invariance assessment for two-factor correlated FOIT (short scale) across countries

\begin{tabular}{|c|c|c|c|c|c|c|c|c|c|}
\hline Scale & Model & $\chi^{2}$ & df & p-value & $\chi^{2} / \mathrm{df}$ & TLI & CFI & RMSEA & $\mathrm{AIC}$ \\
\hline \multirow[t]{2}{*}{ FOIT } & Configural & 201.92 & 39 & .000 & 5.18 & .98 & .99 & .046 & 333.92 \\
\hline & Partial metric & 202.77 & 45 & .000 & 4.51 & .98 & .99 & .042 & 322.77 \\
\hline
\end{tabular}

\subsection{Extending Hille et al.'s (2015) Findings}

According to Nenkov et al. (2008), the main external criteria for scale shortening are construct validity measures, such as predictive and nomological validity. To assess the predictive validity beyond the results reported by Hille et al. (2015), the current study estimates relationships between the two dimensions of the short FOIT scale and the measures of the three preventionfocused behaviors (Figure 1; see Appendix 4 for items). The full and short FOIT scale are 
assessed in terms of predictive validity. Before assessing the predictive validity of FOIT, the three outcome constructs underwent testing to ensure convergent and discriminant validity, as well as metric invariance. The results of a CFA (Appendix 4) for the U.S. and Japanese data show that the outcomes can be captured suitably for both countries. The overall fit of the CFA models, AVE, and alpha values are all satisfactory. Discriminant validly also can be established for all pairs of constructs. Table 4 provides the correlations between the constructs for the full and short FOIT scales. A measurement equivalence analysis across the U.S. and Japanese samples reveals partial metric invariance for the deflective and disruptive constructs $\left(\Delta \chi^{2}=1.15, \Delta_{\mathrm{df}}=2, p>.5\right)$, as well as for the defensive construct $\left(\Delta \chi^{2}=1.63, \Delta_{\mathrm{df}}=1, p>.2\right)$.

Fig. 1 Conceptual model for FOIT and prevention-focused outcomes

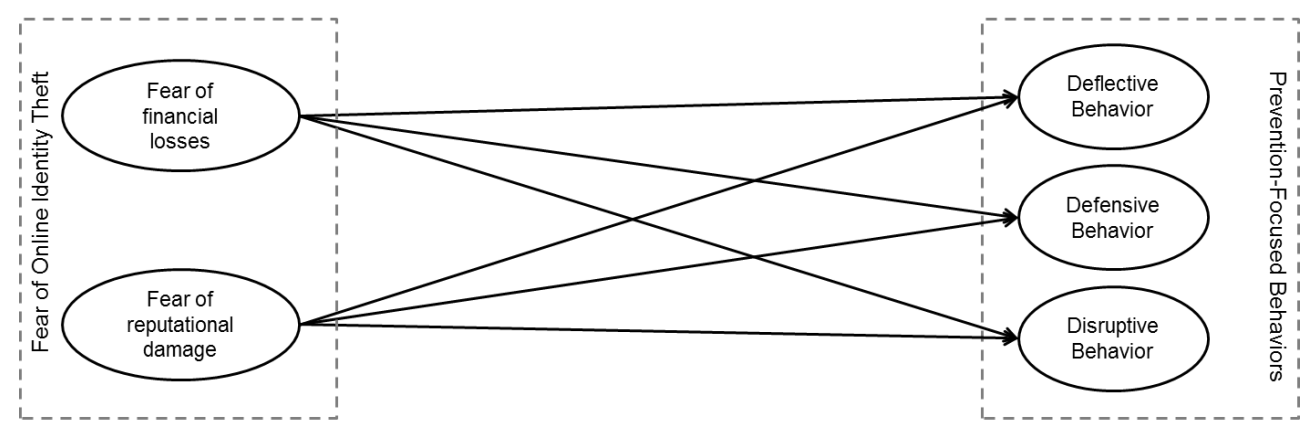

Note: Prevention-focused behaviors were measured in the U.S. and Japanese samples only.

Table 4 Correlations for U.S. and Japan for full and short FOIT scales and outcome constructs

\begin{tabular}{|c|c|c|c|c|c|c|c|c|c|c|}
\hline Construct & \multicolumn{2}{|c|}{1.} & \multicolumn{2}{|c|}{2.} & \multicolumn{2}{|c|}{3.} & \multicolumn{2}{|c|}{4.} & \multicolumn{2}{|c|}{5.} \\
\hline & $\begin{array}{l}\text { Full } \\
\text { scale }\end{array}$ & $\begin{array}{l}\text { Short } \\
\text { scale }\end{array}$ & $\begin{array}{l}\text { Full } \\
\text { scale }\end{array}$ & $\begin{array}{l}\text { Short } \\
\text { scale }\end{array}$ & $\begin{array}{l}\text { Full } \\
\text { scale }\end{array}$ & $\begin{array}{l}\text { Short } \\
\text { scale }\end{array}$ & $\begin{array}{l}\text { Full } \\
\text { scale }\end{array}$ & $\begin{array}{l}\text { Short } \\
\text { scale }\end{array}$ & $\begin{array}{l}\text { Full } \\
\text { scale }\end{array}$ & $\begin{array}{l}\text { Short } \\
\text { scale }\end{array}$ \\
\hline 1. FFL & & & .76 & .71 & .26 & .24 & .34 & .32 & $.10^{*}$ & $.08 \neq$ \\
\hline 2. FRD & .63 & .62 & & 1 & .24 & .24 & .33 & .33 & .22 & .22 \\
\hline 3. Deflective behavior & .33 & .32 & .41 & .41 & & 1 & .63 & & .50 & \\
\hline 4. Defensive behavior & .27 & .26 & .26 & .25 & .68 & .68 & & 1 & .47 & \\
\hline 5. Disruptive behavior & .23 & .22 & .39 & .39 & .44 & .44 & .22 & .22 & & 1 \\
\hline
\end{tabular}

Notes: The U.S. values are in the lower quadrant and the Japanese values are in the upper quadrant; FFL = Fear of financial losses; FRD = Fear of reputational damage; unless states otherwise the correlations at significant at $p<.001$. $* p<.05 . \neq p<.10$.

The results for the predictive validity analyses show that both the FOIT full and short scales yield similar predictive power (see Table 5), in agreement with Ziegler et al. (2014) who argue 
that short scales need not have lower test-criterions correlations than their longer counterparts. In particular, a greater proportion of variation can be explained for the U.S. sample than for the Japanese sample, for both deflective (19\% U.S., 7\% Japan) and disruptive (17\% U.S., 6\% Japan) behaviors. The explanatory power of FOIT for defensive behavior is greater for the Japanese sample, at around 13\%, and a lower R-square value of $9 \%$ applies to the U.S. sample. Thus, the assessment of predictive validity complements the findings provided by Hille et al. (2015), who indicate that $5 \%$ of purchase intentions can be explained uniquely by the two dimensions of FOIT.

In summary, the results of the comprehensive assessment of the 11-item long and 7-item short scale suggest that the FOIT short scale performs at least as well as the original 11-item scale.

Table 5 Predictive validity FOIT (full and short scale), United States and Japan

\begin{tabular}{|c|c|c|c|c|}
\hline \multicolumn{5}{|l|}{ Panel A (FOIT short scale) } \\
\hline \multirow[t]{2}{*}{ Relationship } & \multicolumn{2}{|l|}{$\beta$} & \multicolumn{2}{|c|}{$\mathrm{CR}$} \\
\hline & United States & Japan & United States & Japan \\
\hline FFL $\rightarrow$ Deflective behavior & .07 & .13 & 1.44 & 1.15 \\
\hline FFL $\rightarrow$ Defensive behavior & .14 & .15 & $2.18^{*}$ & $1.76 \neq$ \\
\hline FFL $\rightarrow$ Disruptive behavior & -.06 & -.15 & -.95 & $-1.75 \ddagger$ \\
\hline FRD $\rightarrow$ Deflective behavior & .38 & .15 & $4.36^{* * *}$ & $1.64 \ddagger$ \\
\hline FRD $\rightarrow$ Defensive behavior & .20 & .24 & $3.10 * *$ & $2.80 * *$ \\
\hline FRD $\rightarrow$ Disruptive behavior & .44 & .33 & $6.48^{* * *}$ & $3.93 * * *$ \\
\hline \multicolumn{5}{|l|}{ Summary results } \\
\hline $\mathrm{R}^{2}($ deflective $)=$ & .19 & .07 & & \\
\hline $\mathrm{R}^{2}($ defensive $)=$ & .09 & .13 & & \\
\hline $\mathrm{R}^{2}($ disruptive $)=$ & .17 & .06 & & \\
\hline \multicolumn{5}{|l|}{ Panel B (FOIT full scale) } \\
\hline FFL $\rightarrow$ Deflective behavior & .08 & .18 & 1.23 & $1.77 \ddagger$ \\
\hline FFL $\rightarrow$ Defensive behavior & .14 & .18 & $2.28 *$ & $1.92 \neq$ \\
\hline FFL $\rightarrow$ Disruptive behavior & -.06 & -.15 & -.98 & $-1.67 \neq$ \\
\hline FRD $\rightarrow$ Deflective behavior & .38 & .11 & $4.31 * * *$ & 1.12 \\
\hline FRD $\rightarrow$ Defensive behavior & .20 & .21 & $2.97 * *$ & $2.28 * *$ \\
\hline FRD $\rightarrow$ Disruptive behavior & .45 & .34 & $6.44 * * *$ & $3.73 * * *$ \\
\hline Summary results & & & & \\
\hline $\mathrm{R}^{2}($ deflective $)=$ & .19 & .07 & & \\
\hline$R^{2}($ defensive $)=$ & .09 & .13 & & \\
\hline $\mathrm{R}^{2}($ disruptive $)=$ & .17 & .06 & & \\
\hline
\end{tabular}

Notes: $\mathrm{CR}=$ critical ratio; FFL $=$ Fear of financial losses; FRD = Fear of reputational damage. $\neq p<.10 . * p<.05 . * * p<.01 . * * * p<.001$.

\section{Discussion}

E-businesses continue to spread internationally, even as consumers become increasingly aware of online identity theft, requiring renewed attention to all aspects of consumers' online shopping 
experiences. Hille et al. (2015) introduce a scale to measure FOIT but call for further testing of the generalizability of the FOIT scale, particularly across different populations in other countries. However, since the FOIT scale is relatively new, little information exists on its psychometric properties and there has been little reported data for different populations. Accordingly, acknowledging the increased "demand for short scales" (Ziegler et al. 2014, p. 185), this study aimed to test the reliability and validity of a short FOIT scale in three distinct cultural settings: Germany, the United States, and Japan. Using established criteria, this study demonstrates the robustness and cross-cultural applicability of the FOIT scale. The findings provide support for the usefulness of the short FOIT scale while also highlighting important differences that require consideration when using the scale.

Following Nenkov et al. (2008), this study relied on three criteria (judgmental, internal, external) to evaluate the short FOIT scale. No single criterion can separately reveal the quality of scales and scale items; the three criteria thus appear in conjunction, and overall, items met all three criteria. This study also offers an assessment of the applicability of the scale across three distinct cultures, thereby responding to calls for further research on cross-cultural variation in privacy preferences and beliefs (e.g., Martin and Murphy 2017). The different factor loadings across country samples (Table 2) may reflect sample specificities, different consumption contexts, or cultural variance (Hofstede 2001). Overall, some differences may emerge in the application and replication of the FOIT scale, but the findings, in line with Nenkov et al.'s (2008) proposed criteria, show that the short FOIT scale is a viable instrument for measuring consumers' fear of being victimized by online identity theft. However, the lack of optimal CFA model fit for the Japanese data suggests that FOIT items may require alteration to reflect Japanese consumers' perceptions of FOIT more accurately and increase the content validity. Slightly different items may be needed to capture fear in Japan, where expressions of fear are discouraged as a potential threat to group harmony (Matsumoto 1992). Continued research should address this issue. 


\subsection{Theoretical Implications, Limitations, and Further Research}

Consumers' fear of online identity theft may fit into a broader theory of online consumer shopping behavior. As such, the short FOIT scale could be useful in empirical investigations of theories regarding consumers' reluctance to shop online, as well as theories to explain consumers' unease about sharing personal information in commercial transactions. Moreover, the present research assesses a scale with the potential to facilitate online shopping by offering a better understanding of the reasons that keep some consumers from shopping online. Although this study offers deeper insights into the cross-cultural validation of FOIT, it is not free of limitations, which suggest avenues for still further research.

Scale validation is a continuous process, so additional research should assess the crosscultural validity of the short FOIT scale further. This study also relied on convenience samples in all three countries, yet a different sampling method was applied for the Japanese sample, which produced a younger set of participants. More nationally representative samples might provide insights beyond those achieved through convenience samples. Also, future studies could aim for a standardized data collection procedure to enhance comparability. Specifically, the German data was collected by means of an online survey and the U.S. data through MTurk, the crowd-based Internet service. However, because Japanese crowdsourcing workers are underrepresented on MTurk, it was decided to recruit respondents with the help of Japanese students. An alternative means of assessing the predictive validity of FOIT could use an experimental design where respondents are asked to complete the full or short version of the scale and the same dependent constructs. Such an experimental approach would more directly ascertain if there are differences in predictive validity across the scales. Capturing the full and short scales in a between-subjects design is superior to the standard approach undertaken because participants answering the short version of the scale are not able to see the other (dropped) items of the full scale and thus are not influenced by the presence of these items. Furthermore, although data for this research was collected in relation to online shoppers from the three countries, future studies could undertake a 
validation effort based on real-world online shopping scenarios (cf. Ho and Warkentin 2017; Walsh et al. 2016), using more population representative samples. Another interesting extension might test the short FOIT scale with samples and data from consumers who have and have not had first-hand experience with online identity theft. The two groups may differ in their adapted online shopping behavior when they experience high levels of FOIT. Researchers also might investigate different online shopping contexts (e.g., financial services versus physical goods) or collect longitudinal data. Other variables might enter the nomological network as well, such as website design variables and their effects on FOIT, or electronic word of mouth and share of wallet as outcome variables. Weaving FOIT into a wider nomological net of online shopping behavior could improve understanding of the mechanism by which FOIT affects consumer decision making and outcomes.

Consistent with the notion that replication studies should broaden the theoretical scope (Bonett 2012), this research considered other outcomes in the assessment of predictive validity than Hille et al. (2015). They examined the links between FOIT and online purchase intention, whereas the present study treated prevention-focused behaviors as outcomes. Future replication studies could consider either online purchase intention or prevention-focused behaviors to ensure greater comparability. Furthermore, studies could develop additional FOIT-related insights, particularly related to the mediators and moderators of its antecedent and outcome relationships. For example, consumer age might moderate the relationship between FOIT and its correlates, because older consumers tend to be less willing to divulge and share information online (Malhotra, Kim and Agarwal 2004), which implies a stronger effect of FOIT on outcomes. Replication studies could incorporate mediators and moderators to address these issues, as well as targeting diverse cultures. A possible starting point for further validation would be countries experiencing significant growth in e-commerce, such as China, and nations that are plagued by online information theft, such as Canada, Singapore, Brazil, or the United Kingdom (Jevtic 2015). Lastly, there is always potential pitfalls in scale shortening if the process were to result in short 
form(s) that are a poor reflection of the scale's original conceptualization; with a loss of content validity; with divergent nomological net, diminished predictive power, and loss of applicability to diverse target populations. However, with the adoption of a rigorous scale shortening procedure and criteria (judgmental, internal, and external) suggested by Nenkov et al. (2008), the FOIT short scale does not suffer from these problems.

\subsection{Managerial Implications}

The results support the general notion that firms need to make investments in IT security (Xu et al. 2019) and show that FOIT exists in all three studied countries and thus broadly suggest that consumers' perceptions about potential online identity theft need to be managed appropriately. The short scale enables e-businesses to efficiently measure FOIT and thus can be used to identify FOIT-prone consumers. Once identified, those consumers could be targeted with measures aimed at reducing FOIT. For example, online retailers with many FOIT-prone customers could consider changes to their web shop. Indeed, well-designed online shops and trust-inducing transaction processes instead can bolster consumers' perceptions of quality and trustworthiness and serve as important influences on consumers' willingness to engage in online transactions (Cyr 2014; Riquelme and Román 2014).

The results further reveal that fear of online identity theft can lead to prevention-focused consumer behaviors, which ultimately may have detrimental effects on the firm's bottom line. Considering the emphasis that consumers place on information safety when shopping online (Martin et al. 2017), e-commerce managers must recognize the reasons for and effects of such fears (Crossler et al. 2017). As both a concept and an instrument, FOIT thus is vital to ecommerce management. German, U.S., and Japanese managers should make use of the short FOIT scale to identify potential shortcomings in their created online shopping experiences and transaction processes. If the experience and process lead to consumer unease, the online business might lose customers and suffer revenue losses. Using the short FOIT scale thus makes good 
managerial sense; for example, online retailers could embed the scale in their registration procedures to measure first-time consumers' FOIT.

Online retailers with operations in multiple countries may benefit most from a crossculturally robust short FOIT scale. For such firms, the short scale appears well-suited to gather benchmark data about customers, as well as for conducting periodic comparisons across countries and customer segments. The application of the short FOIT scale also may reveal some necessary adaptations of complaint management and service recovery processes to different national conditions. 


\section{References}

Albashrawi, M., \& Motiwalla, L. (2019). Privacy and personalization in continued usage intention of mobile banking: an integrative perspective. Information Systems Frontiers, 21(5), 10311043.

Avasthy, D. (2014). German police uncover data theft involving 18 million emails and passwords. International Business Times. http://www.ibtimes.co.uk/german-police-uncover-data-theftinvolving-18-million-emails-passwords-1443336. Accessed 28 January 2019.

Bellman, S., Johnson, E. J., Kobrin, S. J., \& Lohse, G. L. (2004). International differences in information privacy concerns: A global survey of consumers. The Information Society: An International Journal, 20(5), 313-324.

Berendt, B., Günther, O., \& Spiekermann, S. (2005). Privacy in e-commerce: Stated preferences vs. actual behavior. Communications of the ACM, 48(4), 101-106.

Berthon, P., Pitt, L., Ewing, M., \& Carr, C. L. (2002). Potential research space in MIS: A framework for envisioning and evaluating research replication, extension, and generation. Information Systems Research, 13(4), 416-427.

Bonett, D. G. (2012). Replication-Extension Studies. Current Directions in Psychological Science, 21(6), 409-412.

Breaugh, J. A., \& Colihan, J. P. (1994). Measuring facets of job ambiguity: Construct validity evidence. Journal of Applied Psychology, 79(2), 191-202.

Casler, K., Bickel, L., and Hackett, E. E. (2013). Separate but equal? A comparison of participants and data gathered via Amazon's MTurk, social media, and face-to-face behavioral testing, Computers in Human Behavior, 29(6), 2156-2160.

Crossler, R. E., Bélanger, F., \& Ormond, D. (2019). The quest for complete security: An empirical analysis of users' multi-layered protection from security threats. Information Systems Frontiers, 21(2), 343-357. 
Cyr, D. (2014). Return visits: a review of how Web site design can engender visitor loyalty. Journal of Information Technology, 29(1), 1-26.

Cyr, D., Head, M., \& Larios, H. (2010). Colour appeal in website design within and across cultures: A multi-method evaluation. International Journal of Human-Computer Studies, $68(1), 1-21$.

Davis, L., Wang, S. \& Lindridge, A. (2008). Culture influences on emotional responses to on-line store atmospheric cues. Journal of Business Research, 61(8), 806-812.

Edwards, P., Roberts, I., Sandercock, P., \& Frost, C. (2004). Follow-up by mail in clinical trials: does questionnaire length matter?. Controlled Clinical Trials, 25(1), 31-52.

ENISA (2014). 16 million e-identities and passwords theft. News Flash, January 22, 2014. European Union Agency for Network and Information Security. https://www.enisa.europa.eu/media/news-items/news-flash-statement-re-16-million-eidentities-passwords-theft. Accessed 27 January 2019.

European Commission (2018). European Commission - Statement. http://europa.eu/rapid/pressrelease_STATEMENT-18-4548_en.htm. Accessed 1 November 2018.

Federal Office for Information Security (2018). The State of IT Security in Germany 2018. https://www.bsi.bund.de/SharedDocs/Downloads/EN/BSI/Publications/Securitysituation/ITSecurity-Situation-in-Germany-2018.pdf?_blob=publicationFile\&v=3. Accessed 12 February 2019.

Fico (2017). FICO Survey: US Consumers Fear Bank Fraud and ID Theft More than Terrorist Attack. https://www.fico.com/en/newsroom/fico-survey-us-consumers-fear-bank-fraud-andid-theft-more-than-terrorist-attack-07-27-2017. Accessed 18 January 2019.

Fornell, C., \& Larcker, D. F. (1981). Evaluating structural equation models with unobservable variables and measurement error. Journal of Marketing Research, 18(1), 39-50. 
FTC (Federal Trade Commission) (2018). FTC Releases Annual Summary of Consumer Complaints, https://www.ftc.gov/news-events/press-releases/2018/03/ftc-releases-annualsummary-complaints-reported-consumers. Accessed 4 January 2019.

Green, D., \& Hanbury, M. (2018). If you shopped at these 16 stores in the last year, your data might have been stolen. Business Insider, Aug 22, 2018. https://www.businessinsider.com/data-breaches-2018-4?r=US\&IR=T. Accessed 10 December 2018.

Gupta, B., Iyer, L. S., \& Weisskirch, R. S. (2010). Facilitating global e-commerce: a comparison of consumers' willingness to disclose personal information online in the US and in India. Journal of Electronic Commerce Research, 11(1), 41-52.

Henningham, J. P. (1996). A 12-item scale of social conservatism. Personality and Individual Differences, 20(4), 517-519.

Henseler, J., Ringle, C. M., \& Sarstedt, M. (2015). A new criterion for assessing discriminant validity in variance-based structural equation modeling. Journal of the Academy of Marketing Science, 43(1), 115-135.

Herpin, T. (2018). The top 10 E-Commerce markets you should target in the world. Aug 7, 2018. E-commerce Nation (ECN). https://www.ecommerce-nation.com/the-top-10-e-commercemarkets-you-should-target-in-the-world/. Accessed 5 December 2018.

Hille, P., Walsh, G. \& Cleveland, M. (2015). Consumer fear of online identity theft: Scale development and validation. Journal of Interactive Marketing, 30(May), 1-19.

Hinkin, T. R. (1995). A review of scale development practices in the study of organizations. Journal of Management, 21(5), 967-988.

Hinz, O., Nofer, M., Schiereck, D., \& Trillig, J. (2015). The influence of data theft on the share prices and systematic risk of consumer electronics companies. Information \& Management, $52(3), 337-347$. 
Ho, S. M., \& Warkentin, M. (2017). Leader's dilemma game: An experimental design for cyber insider threat research. Information Systems Frontiers, 19(2), 377-396.

Hofstede, G. (2001). Culture's consequences: Comparing values, behaviors, institutions, and organization across nations. Thousand Oaks, CA: Sage.

Hofstede, G. (2019). Hofstede Insights. https://www.hofstede-insights.com/product/comparecountries/. Accessed 1 February 2019.

Jevtic, A. (2015). 11 countries with the highest rates of identity theft in the world. http://www.insidermonkey.com/blog/11-countries-with-the-highest-rates-of-identity-theft-inthe-world-351940/. Accessed 26 December 2018.

Kulach, K. (2019). What turned ASOS online store into a global ecommerce giant? https://www.webinterpret.com/us/blog/asos-online-store-global-ecommerce-success/. Accessed 22 September 2019.

Lee, M., \& Lee, J. (2012). The impact of information security failure on customer behaviors: A study on a large-scale hacking incident on the internet. Information Systems Frontiers, 14(2), 375-393.

Lee, G.-G., \& Lin, H.-F. (2005). Customer perceptions of e-service quality in online shopping. International Journal of Retail \& Distribution Management 33(2), 161-176.

Lin, W. H., Wang, P., \& Tsai, C. F. (2016). Face recognition using support vector model classifier for user authentication. Electronic Commerce Research and Applications, 18, 71-82.

Littleton, C. (2017). HBO Invests Big in Europe, Asia and Latin American Channels. https://variety.com/2017/tv/news/hbo-networks-europe-asia-latin-america-1202590526/. Accessed 18 December 2018.

Macy’s (2016). International Shipping, https://www.customerservicemacys.com/app/answers/detail/a_id/5363/?lid=glbtopnav_details-intl. Accessed 9 February 2019. 
Madden, M. (2014). More online Americans say they’ve experienced a personal data breach. PewReseachCenter, http://www.pewresearch.org/fact-tank/2014/04/14/more-onlineamericans-say-theyve-experienced-a-personal-data-breach/. Accessed 4 January 2019.

Malhotra, N. K., Kim, S. S., \& Agarwal, J. (2004). Internet users' information privacy concerns (IUIPC): The construct, the scale, and a causal model. Information Systems Research, 15(4), 336-355.

Martin, K. D., Borah, A., \& Palmatier, R. W. (2017). Data privacy: Effects on customer and firm performance. Journal of Marketing, 81(1), 36-58.

Martin, K. D., \& Murphy, P. E. (2017). The role of data privacy in marketing. Journal of the Academy of Marketing Science, 45, 135-155.

Matsumoto, D. (1992). More evidence for the universality of a contempt expression. Motivation \& Emotion, 16(4), 363-368.

Mazaheri, E., Richard, M. O., Laroche, M., \& Ueltschy, L. C. (2014). The influence of culture, emotions, intangibility, and atmospheric cues on online behavior. Journal of Business Research, 67(3), 253-259.

Nenkov, G. Y., Morrin, M., Schwartz, B., Ward, A., \& Hulland, J. (2008). A short form of the Maximization Scale: Factor structure, reliability and validity studies. Judgment and Decision Making, 3(5), 371-388.

Pascual, A., Marchini, K., \& Miller, S. (2018). 2018 Identity Fraud: Fraud Enters a New Era of Complexity, https://www.javelinstrategy.com/coverage-area/2018-identity-fraud-fraudenters-new-era-complexity. Accessed 12 February 2019.

Postmes, T., Haslam, S. A., \& Jans, L. (2013). A single-item measure of social identification: Reliability, validity, and utility. British Journal of Social Psychology, 52(4), 597-617.

Rigby, C. (2019). Gear4Music to improve its distribution processes as it looks to deal with its fast growth. Internet Retailing, https://internetretailing.net/strategy-and-innovation/strategy-and- 
innovation/gear4music-to-improve-its-distribution-processes-as-it-looks-to-deal-with-its-fastgrowth-19384. Accessed 8 September 2019.

Riquelme, I. P., \& Román, S. (2014). Is the influence of privacy and security on online trust the same for all type of consumers?. Electronic Markets, 24(2), 135-149.

Roberts, L. D., Indermaur, D., \& Spiranovic, C. (2013). Fear of cyber-identity theft and related fraudulent activity. Psychiatry, Psychology and Law, 20(3), 315-328.

Ruvio, A., Shoham, A., \& Makovec Brencic, M. (2008). Consumers' need for uniqueness: shortform scale development and cross-cultural validation. International Marketing Review, 25(1), $33-53$.

Smith, R., Deitz, G., Royne, M. B., Hansen, J. D., Grünhagen, M. \& Witte, C. (2013). Crosscultural examination of online shopping behavior: A comparison of Norway, Germany, and the United States. Journal of Business Research, 66(3), 328-335.

Stahl, G. K., \& Caligiuri, P. (2005). The effectiveness of expatriate coping strategies: the moderating role of cultural distance, position level, and time on the international assignment. Journal of Applied Psychology, 90(4), 603-615.

Smith, G. T., McCarthy, D. M., \& Anderson, K. G. (2000). On the sins of short-form development. Psychological Assessment, 12(1), 102-111.

Steenkamp, J. B. E., \& Baumgartner, H. (1998). Assessing measurement invariance in crossnational consumer research. Journal of Consumer Research, 25(1), 78-107.

Sun, T. (2011). The roles of trust and experience in consumer confidence in conducting ecommerce: A cross-cultural comparison between France and Germany. International Journal of Consumer Studies, 35(3), 330-337.

Targett, E. (2018). 6 Months, 945 Data Breaches, 4.5 Billion Records, Computer Business Review, https://www.cbronline.com/news/global-data-breaches-2018. Accessed 16 September 2019. 
The Japan Times (2013). Yahoo Japan suspects vast ID theft, May 18, http://www.japantimes.co.jp/news/2013/05/18/national/crime-legal/yahoo-japan-suspectsvast-id-theft/. Accessed 22 January 2016.

The Japan Times (2016). At least 2 million sets of personal data feared stolen in 2015 cyberattacks. January 4, http://www.japantimes.co.jp/news/2016/01/04/national/least-2million-sets-personal-data-feared-leaked-cyberattacks-2015/. Accessed 22 November 2018. The Japan Times (2018). 320,000 pieces of customer data stolen from 400 lodging providers in Japan. June 28, https://www.japantimes.co.jp/news/2018/06/28/national/crime-legal/320000bits-customer-info-lodging-providers-japan-stolen/\#.XGK8pHd2t2M. Accessed 12 February 2019.

Tsai, J. Y., Egelman, S., Cranor, L., \& Acquisti, A. (2011). The effect of online privacy information on purchasing behavior: An experimental study. Information Systems Research, 22(2), 254-268.

Van Auken, S., Barry, T. E., \& Bagozzi, R. P. (2006). A cross-country construct validation of cognitive age. Journal of the Academy of Marketing Science, 34(3), 439-455.

Vernuccio, M., Pagani, M., Barbarossa, C., \& Pastore, A. (2015). Antecedents of brand love in online network-based communities. A social identity perspective. Journal of Product \& Brand Management, 24(7), 706-719.

Walsh, G., Northington, W. M., Hille, P., \& Dose, D. (2015). Service employees’ willingness to report complaints scale: Cross-country application and replication. Journal of Business Research, 68(3), 500-506.

Walsh, G., Beatty, S. E., \& Shiu, E. M. (2009). The customer-based corporate reputation scale: Replication and short form. Journal of Business Research, 62(10), 924-930.

Walsh, G., Schaarschmidt, M., \& Von Kortzfleisch, H. (2016). Employees' company reputationrelated social media competence: Scale development and validation. Journal of Interactive Marketing, 36, 46-59. 
Weijters, B., Geuens, M., \& Schillewaert, N. (2009). The proximity effect: The role of inter-item distance on reverse-item bias. International Journal of Research in Marketing, 26(1), 2-12.

Wirtz, J., \& Lwin, M. O. (2009). Regulatory focus theory, trust, and privacy concern. Journal of Service Research, 12(2), 190-207.

Xu, H., \& Gupta, S. (2009). The effects of privacy concerns and personal innovativeness on potential and experienced customers' adoption of location-based services. Electronic Markets, 19(2-3), 137-149.

Xu, F., Luo, X. R., Zhang, H., Liu, S., \& Huang, W. W. (2019). Do Strategy and Timing in IT Security Investments Matter? An Empirical Investigation of the Alignment Effect. Information Systems Frontiers, 21(5), 1069-1083.

Zafar, H., Ko, M., \& Osei-Bryson, K. (2012). Financial impact of information security breaches on breached firms and their non-breached competitors. Information Resources Management Journal, 25(1), 21-37.

Zafar, H., Ko, M. S., \& Osei-Bryson, K. M. (2016). The value of the CIO in the top management team on performance in the case of information security breaches. Information Systems Frontiers, 18(6), 1205-1215.

Ziegler, M., Kemper, C. J., \& Kruyen, P. (2014). Short Scales - Five Misunderstandings and Ways to Overcome Them, Journal of Individual Differences, 35(4), 185-189. 
Appendix 1 Readability assessment (means), item-to-subscale correlations, and item-to-total correlation

\begin{tabular}{|c|c|c|c|c|c|c|}
\hline & $\begin{array}{l}\text { Readability } \\
\text { (Study 1): } \\
\text { Germany }\end{array}$ & $\begin{array}{l}\text { Germany: } \\
\text { ISC / ITC }\end{array}$ & $\begin{array}{l}\text { Readability } \\
\text { (Study 2): } \\
\text { United States }\end{array}$ & $\begin{array}{l}\text { United } \\
\text { States: } \\
\text { ISC / ITC }\end{array}$ & $\begin{array}{l}\text { Readability } \\
\text { (Study 3): Japan }\end{array}$ & $\begin{array}{l}\text { Japan: } \\
\text { ISC / ITC }\end{array}$ \\
\hline \multicolumn{7}{|l|}{ Fear of financial losses (FFL) } \\
\hline $\begin{array}{l}\text { (1) I am afraid that somebody could steal my money while I am } \\
\text { transferring my personal data online. }\end{array}$ & 5.44 & $.84 / .82$ & 5.70 & $.86 / .84$ & 5.14 & $.74 / .73$ \\
\hline $\begin{array}{l}\text { (2) I am scared that a criminal could use my bank account number to do } \\
\text { online shopping in my name. }{ }^{\text {a }}\end{array}$ & 6.13 & $.85 / .83$ & 5.73 & $.89 / .87$ & 5.81 & $.84 / .82$ \\
\hline $\begin{array}{l}\text { (3) I am scared that a criminal could use my credit card account number } \\
\text { to do online shopping in my name. }{ }^{\text {a }}\end{array}$ & 6.34 & $.80 / .78$ & 6.03 & $.90 / .87$ & 5.86 & $.86 / .84$ \\
\hline $\begin{array}{l}\text { (4) I am frightened that somebody could do online shopping at my } \\
\text { expense. }{ }^{\text {a }}\end{array}$ & 5.75 & $.85 / .82$ & 5.35 & $.88 / .86$ & 5.60 & $.86 / .84$ \\
\hline $\begin{array}{l}\text { (5) I am worried about an unauthorized person making online purchases } \\
\text { using my personal data. }{ }^{\text {a }}\end{array}$ & 5.91 & $.86 / .83$ & 5.60 & $.88 / .85$ & 5.58 & $.86 / .85$ \\
\hline $\begin{array}{l}\text { (6) I am scared that when I have to give my credit card number to shop } \\
\text { online that it could be misused. }\end{array}$ & 5.97 & $.80 / .78$ & 5.45 & $.88 / .85$ & 5.60 & $.80 / .80$ \\
\hline $\begin{array}{l}\text { (7) I am scared that when I have to give my bank account number to shop } \\
\text { online that it could be misused. }\end{array}$ & 6.22 & $.79 / .76$ & 5.80 & $.81 / .80$ & 5.91 & $.82 / .83$ \\
\hline $\begin{array}{l}\text { (8) The thought that a stranger could gain access to my customer account } \\
\text { at an online store by using my personal data frightens me. }\end{array}$ & 5.38 & $.79 / .81$ & 5.45 & $.78 / .80$ & 5.60 & $.76 / .80$ \\
\hline \multicolumn{7}{|l|}{ Fear of reputational damage (FRD) } \\
\hline $\begin{array}{l}\text { (9) I am frightened of somebody using my personal data on the Internet } \\
\text { in order to run me down. }{ }^{\text {a }}\end{array}$ & 5.50 & $/ .71$ & 5.10 & $/ .59$ & 5.50 & $/ .81$ \\
\hline $\begin{array}{l}\text { (10) I am very worried that the unauthorized use of my personal data } \\
\text { online could damage my reputation. }{ }^{\text {a }}\end{array}$ & 5.19 & $/ .76$ & 5.50 & $/ .62$ & 5.23 & $/ .78$ \\
\hline $\begin{array}{l}\text { (11) I am worried about my reputation being damaged due to the illegal } \\
\text { use of my personal data online. }{ }^{\text {a }}\end{array}$ & 5.47 & $/ .75$ & 5.40 & $/ .61$ & 5.40 & $/ .78$ \\
\hline
\end{tabular}

Note: ${ }^{\text {a }}=$ items chosen for 7-item FOIT short scale; ISC = item-to-subscale correlation; ITC = item-to-total correlation 
Appendix 2 Discriminant validity between FFL and FRD (HTMT ratios)

\begin{tabular}{llllllll}
\hline & \multicolumn{2}{c}{ Germany } & \multicolumn{2}{c}{ United States } & \multicolumn{2}{c}{ Japan } \\
\hline & Full & Short & Full & Short & Full & Short \\
& scale & scale & scale & scale & scale & scale \\
\hline & \multicolumn{7}{c}{ Fear of financial losses (FFL) } \\
$\begin{array}{l}\text { Fear of reputational } \\
\text { damage (FRD) }\end{array}$ & .89 & .53 & .68 & .39 & .83 & .47 \\
\hline
\end{tabular}


Appendix 3 Average factor loadings

\begin{tabular}{lccc}
\hline & $\begin{array}{c}\text { Germany: Hille et } \\
\text { al. (2015) study 3 }\end{array}$ & $\begin{array}{c}\text { Study 2: United } \\
\text { States }\end{array}$ & Study 3: Japan \\
\hline FOIT long scale (11 items) & .86 & .86 & .86 \\
\hline FOIT short scale (7 items) & .89 & .86 & .91 \\
\hline
\end{tabular}


Appendix 4 Standardized CFA factor loadings and summary psychometric data for outcome constructs

\begin{tabular}{|c|c|c|}
\hline Construct and items / Fit statistics & $\begin{array}{l}\text { Study 2: } \\
\text { United } \\
\text { States }\end{array}$ & $\begin{array}{l}\text { Study 3: } \\
\text { Japan }\end{array}$ \\
\hline Deflective behavior & $\begin{array}{c}\alpha=.70 \\
\mathrm{AVE}=.54\end{array}$ & $\begin{aligned} \alpha & =.74 \\
\mathrm{AVE} & =.63\end{aligned}$ \\
\hline (1) I will set my server level e-mail filter to discard e-mails from the e-retailer's web site. & .76 & .64 \\
\hline $\begin{array}{l}\text { (2) I will disguise my identity to prevent the e-retailer's web site from finding me in } \\
\text { future. }\end{array}$ & .71 & .92 \\
\hline Defensive behavior & $\begin{array}{c}\alpha=.83 \\
\mathrm{AVE}=.67\end{array}$ & $\begin{aligned} \alpha & =.81 \\
\mathrm{AVE} & =.61\end{aligned}$ \\
\hline $\begin{array}{l}\text { (3) I will ask the e-retailer's web site to remove my name and address from their mailing } \\
\text { list. }\end{array}$ & .93 & .86 \\
\hline $\begin{array}{l}\text { (4) I will ask the e-retailer's web site not to share my name or other personal information } \\
\text { with other companies. }\end{array}$ & .52 & .58 \\
\hline $\begin{array}{l}\text { (5) I will take action to have my name removed from the e-retailer's web site's mailing } \\
\text { list. }\end{array}$ & .94 & .86 \\
\hline Disruptive behavior & $\begin{array}{c}\alpha=.89 \\
\mathrm{AVE}=.74\end{array}$ & $\begin{aligned} \alpha & =.93 \\
\mathrm{AVE} & =.81\end{aligned}$ \\
\hline $\begin{array}{l}\text { (6) I will say negative things about the e-retailer's web site in Internet chat rooms and/or } \\
\text { online bulletins. }\end{array}$ & .83 & .86 \\
\hline $\begin{array}{l}\text { (7) I will flood the e-retailer's web site's customer support account with negative } \\
\text { messages. }\end{array}$ & .84 & .95 \\
\hline (8) I will send highly negative messages to the e-retailer's web site. & .91 & .89 \\
\hline \multicolumn{3}{|l|}{ CFA fit statistics } \\
\hline$\chi^{2}$ & 60.12 & 51.21 \\
\hline Degree of freedom & 17 & 17 \\
\hline CFI & .98 & .98 \\
\hline TLI & .97 & .96 \\
\hline RMSEA & .072 & .078 \\
\hline RMSEA 90\% CI Lower bound & .052 & .054 \\
\hline RMSEA $90 \%$ CI Upper bound & .092 & .103 \\
\hline
\end{tabular}

Notes: $\alpha=$ Cronbach's alpha; AVE = average variance extracted; CI = confidence interval. Items 4 and 7 were freed to achieve partial metric invariance. 